REVISTA DE DERECHO UNED, NÚM. 27, 2021

\title{
INVESTIGACIONES BIOMÉDICAS Y DIGNIDAD HUMANA: LOS LÍMITES A LA LIBERTAD DE INVESTIGACIÓN
}

\author{
BIOMEDICAL RESEARCH AND HUMAN DIGNITY: THE LIMITS \\ TO THE FREEDOM OF RESEARCH
}

Luis Alfonso SÁNCHEZ MEgía

Doctorando del Programa de Derecho de la UNED

Sumario: Introducción. 1. Investigaciones biomédicas: avances no exentos de peligros. 2. Ser humano: ser digno. 2.1. Introducción. 2.2. La dignidad del ser humano. 3. Limites a la libertad de investigación. 4. Conclusión final. Bibliografía.

Resumen: El legítimo ejercicio del derecho fundamental a la libertad de investigación ha dado lugar desde hace décadas al surgimiento y desarrollo de importantes avances en el terreno de las ciencias biomédicas. En algunos casos estos avances conllevan efectos muy positivos para la vida del hombre, pero al mismo tiempo generan interrogantes de hondo calado como consecuencia del enorme poder manipulador que posibilitan sobre los seres humanos. El clima de incertidumbre y temor que propician dichos adelantos impone que desde la ética y el derecho se ofrezcan soluciones serias que, en todo caso, deberán tener siempre como referente insalvable la dignidad de las personas. Este es precisamente el objetivo perseguido con este trabajo: a partir del citado referente, ofrecer una explicación sencilla y clara pero al mismo tiempo rigurosa acerca de los límites éticos y jurídicos que deben imponerse a la libertad de investigación en el ámbito biomédico. 
Palabras clave: Libertad de investigación, avances biomédicos, dignidad, límites.

Abstract: The legitimate exercise of the fundamental right to freedom of research has led for decades to the emergence and development of important advances in the field of biomedical sciences. In some cases, these advances have very positive effects on human life, but at the same time they generate profound questions as a consequence of the enormous manipulative power they may have over human beings. The climate of uncertainty and fear that these advances foster imposes that serious solutions must be offered from ethics and law, which, in any case, must always have the dignity of the people as an insurmountable reference. This is precisely the objective pursued with this work: based on the aforementioned reference, to offer a simple and clear but at the same time rigorous explanation of the ethical and legal limits that must be imposed on freedom of research in the biomedical field.

Keywords: Freedom of research, biomedical advances, dignity, limits.

Recepción original: 18-6-2020

Aceptación original: 5-8-2020

\section{INTRODUCCIÓN}

El mundo que nos ha tocado vivir nos brinda la posibilidad casi día a día de ser espectadores privilegiados de los deslumbrantes avances que ofrece la ciencia en muy diversos terrenos. De estos, son los relacionados con los aspectos más conectados con la vida humana los que nos están permitiendo acaparar un poder descomunal sobre nosotros mismos y sobre nuestra propia especie. Esta situación, como es normal, está haciendo surgir de manera continua diversos interrogantes ante los que la ética y el derecho no pueden permanecer impasibles pues la propia sociedad exige soluciones que queden blindadas por medio de las normas jurídicas. Nosotros trataremos aquí de dar respuesta a algunas de las primeras cuestiones que deben resolverse sobre este particular, tales como: ¿qué clase de límites pueden imponerse al amplio abanico de alternativas que proponen las nuevas tecnologías?, ¿cabe incluso hablar de requisitos o condiciones cuyo objeto sea prohibir o restringir determinadas prácticas en el ámbito de las ciencias de la vida (biología, medicina, etc.)?, ¿es posible limitar la libertad de investigación? Veremos como 
la respuesta dependerá en definitiva de qué entendamos por ser humano y de qué valor atribuyamos a su vida. No obstante, comencemos lo primero comprobando como los adelantos biotecnológicos producen efectos muy positivos para la vida del hombre, pero suscitan al mismo tiempo grandes dudas por las consecuencias dañinas que asimismo pueden originar.

\section{INVESTIGACIONES BIOMÉDICAS: AVANCES NO EXENTOS DE PELIGROS}

Los grandes procesos de transformación que acontecen en la sociedad, ya sean de tipo económico, político o ideológico, se ven acompañados normalmente de importantes avances en el terreno de la ciencia y de la tecnología. Sin embargo, una de las diferencias más destacadas entre los actuales procesos de cambio y los que tuvieron lugar en épocas pasadas, es que mientras algunos de esos cambios se produjeron con lentitud, en nuestros días la velocidad de los mismos se ha acelerado enormemente. Las transformaciones son tan profundas y vertiginosas, que nuestra forma de pensar, de actuar y de relacionarnos los unos con los otros está cambiando radicalmente, hasta el punto de que nuestra sociedad resulta irreconocible. Tal circunstancia ha contribuido decididamente a tener la certeza de que nos encontramos ante una nueva época caracterizada por la revolución tecnológica y cuyas consecuencias pueden ser tan amplias y decisivas como imprevisibles. Asimismo, es ya una evidencia incontestable que esta situación acarrea un cada vez más acentuado distanciamiento entre países ricos y pobres, aumentando las desigualdades sociales, incluso en el seno de las sociedades más prósperas, y, por ende, el dramático nivel de injusticia que muy lamentablemente tenemos en este mundo.

Los avances científicos de los últimos tiempos se han producido, digamos, tanto hacia el exterior del ser humano como hacia su interior. En el primer caso, el hombre contemporáneo ha sido testigo, por ejemplo, de la revolución nuclear, así como de los sorprendentes cambios operados en el terreno de la informática y de la comunicación. En el segundo, hemos profundizado extraordinariamente en el conocimiento de la vida humana, lo que nos ha permitido averiguar los misterios de su origen y funcionamiento ${ }^{1}$. En este sentido,

1 JUNQUERA DE ESTÉFANI, Rafael: "Los Derechos Humanos en la era de la Biotecnología”. En MARTÍNEZ MORÁN, Narciso (ed.): Utopía y realidad de los Derechos Humanos en el cincuenta aniversario de su Declaración Universal. Madrid, UNED, 1999, p. 89. 
desde finales del pasado siglo y más claramente con el arranque del presente, la atención de los expertos se polariza en torno a los descubrimientos en el campo de la medicina y la genética. De hecho, como señala el profesor José Félix Tezanos, los científicos consideran que será este componente el que marcará los grandes y trascendentales cambios sociales de los próximos lustros ${ }^{2}$. Tales avances abren a los seres humanos ${ }^{3}$ nuevos horizontes de esperanza en cuanto a la mejora de la calidad de vida ${ }^{4}$ y a la posibilidad de superar las enfermedades con menos sufrimiento y dolor. Así, cabe decir que uno de los retos más importantes que tiene ante sí la medicina es la prevención, el diagnóstico y el tratamiento de las principales alteraciones de la salud, y en ello debe jugar un papel crucial el conocimiento del genoma humano ${ }^{5}$ las consecuentes terapias curativas y predictivas que de ello se deriven. Hay que tener en cuenta que la secuenciación y recombinación del ADN tiene ya hoy múltiples aplicaciones biomédicas, entre las que se encuentran el descubrimiento de casi cinco mil enfermedades mono/poligenéticas ${ }^{6} \mathrm{o}$ la posibilidad de curar al paciente mediante la sustitución o modificación funcional de los genes defectuosos. Mas, los aspectos positivos de los progresos médicos no se quedan ahí. Las diversas técnicas de fertilización humana asistida (inseminación artificial, generación in vitro, congelación y utilización de óvulos fecundados, etc.), que permiten a muchas parejas el tener hijos que no pueden engendrar por la vía de la unión conyugal; la posibilidad de generar tejidos y órganos a partir de la investigación con células madre y con células embriona-

2 TEZANOS TORTAJADA, José Félix: La sociedad dividida. Estructuras de clases y desigualdades en las sociedades tecnológicas. Madrid, Biblioteca Nueva, 2005, p. 56.

3 En este trabajo, como tendremos ocasión de ir viendo, utilizaremos indistintamente las expresiones ser humano y persona.

4 Piénsese, por otra parte, en el tremendo impacto que estos progresos vienen produciendo en el terreno de la agricultura, la ganadería, la transformación industrial y, desde luego, en la lucha contra las enfermedades y la muerte. DE CASTRO CID, Benito: "Derechos Humanos. Biotecnología. Derechos Humanos: una compleja interacción circular". En MARCOS DEL CANO, Ana María (coord.): Bioética y Derechos Humanos. Madrid, UNED, 2011, p. 48. Estos campos, como dice el profesor Benito de Castro en la obra citada, "están registrando la invasión más intensa de los avances biotecnológicos”. Ibídem, p. 50.

5 Para aproximarse al conocimiento del denominado "Proyecto Genoma Humano" pueden consultarse, de entre la abundante bibliografía publicada, las obras siguientes: APARISI MIRALLES, Ángela: El Proyecto Genoma Humano: algunas reflexiones sobre sus relaciones con el Derecho. Valencia, Tirant lo Blanch, 1997; BLÁZQUEZ RUIZ, Javier: Derechos Humanos y Proyecto Genoma. Granada, Comares, 1999; LEE, Thomas F.: El Proyecto Genoma Humano. Barcelona, Gedisa, 2000 (traducción de José A. Álvarez) y la Revista de Derecho y Genoma Humano. Bizkaia, Fundación BBV.

6 RODRÍGUEZ MERINO, José María: Ética y derechos humanos en la era biotecnológica. Madrid, Dykinson, 2008, pp. 129 y 130. 
rias, algo altamente beneficioso de cara a efectuar trasplantes en seres humanos; o, en fin, los avances farmacológicos y las nuevas técnicas de reanimación y tratamiento del dolor, que permitirán llevar una vida más digna al enfermo terminal, son todos ellos ejemplos de las ventajas que suponen para el hombre dichos progresos ${ }^{7}$. Tal es la relevancia de los mismos que hay incluso quien se atreve a aventurar que la genética es "la única ciencia capaz de asegurar a la especie humana un dominio sobre su propio destino evolutivo" .

Sin embargo, el trepidante desarrollo de las investigaciones biomédicas, con descubrimientos de vital importancia para las personas, ha supuesto al mismo tiempo una auténtica revolución a nivel ético y jurídico. Por una parte estos descubrimientos despiertan, como hemos señalado, grandes esperanzas en el despegue de la calidad de vida, pero por otra han dado lugar al surgimiento de un clima de incertidumbre pues se desconocen los potenciales peligros que pueden acarrear para la humanidad. Prácticas como el aborto eugenésico, la eutanasia, la clonación u otra serie de agresiones contra la dignidad del ser humano (esterilización, anticoncepción, eliminación de embriones congelados, etc.), son ejemplos lo suficientemente ilustrativos como para hacernos ver que muchos de los últimos avances que se han producido en el campo de la medicina, verdaderamente impensables hace tan solo unas décadas, repercuten de una u otra forma sobre determinados derechos humanos, especialmente sobre el derecho a la vida. La posible aplicación sobre las personas adultas (y, en general, sobre todas aquellas que ya han superado el estado embrionario) de los resultados de tales investigaciones, hace que afloren con mayor inmediatez y patencia profundas controversias de naturaleza moral, al margen de las dudas de tipo legal que puedan suscitar. Así, sucede por ejemplo que debido a la complejidad y multiplicidad de tratamientos y de técnicas aplicables, el paciente y el médico se encuentran ante un amplio abanico de posibilidades de actuación, algunas de las cuales pueden aumentar la "cantidad" de vida pero no su calidad". Esta situación ha dado pie a una de las notas características de la medicina actual, la preva-

7 MARTÍNEZ MORÁN, Narciso: "Los derechos humanos como límite a la libertad en las investigaciones biomédicas». En JUNQUERA DE ESTÉFANI, Rafael (dir.): Bioética y bioderecho. Reflexiones jurídicas ante los retos bioéticos. Granada, Comares, 2008, pp. 64 y 65.

8 DE MIGUEL BERIAIN, Íñigo: El embrión y la biotecnología. Un análisis éticojurídico. Granada, Comares, 2004, p. 2.

9 MARCOS DEL CANO, Ana María: "La autonomía del paciente en los supuestos de incapacidad”. En JUNQUERA DE ESTÉFANI, Rafael (dir.): Bioética y bioderecho. Reflexiones jurídicas ante los retos bioéticos. Op. cit., p. 183. 
lencia de la autonomía del paciente a la hora de tomar decisiones en el curso de su enfermedad.

En efecto, el panorama que acabamos de describir ha propiciado que en los últimos años estemos asistiendo a una paulatina transformación en la práctica de la medicina. Los adelantos a nivel tecnológico han desembocado en un replanteamiento del modus operandi médico en cuanto a quién puede y debe tomar las decisiones que afectan al cuerpo de la persona. La respuesta que tradicionalmente se ha dado a esta pregunta es que le corresponde a los profesionales sanitarios y, en último caso, a los familiares. Sin embargo, desde hace varias décadas se viene imponiendo la idea de que es el paciente el titular de dicha prerrogativa. Se ha pasado, pues, de un modelo de relación médico-paciente prácticamente unidireccional, en el que el primero proporciona al enfermo la información que estima más adecuada acerca de la solución terapéutica idónea para la enfermedad, y este, de manera sumisa y obediente, se limita a acatar las decisiones de aquel (modelo paternalista), a un modelo más simétrico o deliberativo, caracterizado por el auténtico proceso dialógico entablado entre ambas partes, y que permitirá que el facultativo pueda ayudar al paciente a ir descubriendo lo que resulta más beneficioso para sí mismo y, finalmente, a decidir de manera autónoma y responsable el tratamiento a seguir (modelo deliberativo).

Vemos, pues, que el progresivo desarrollo al que nos venimos refiriendo ha supuesto una radical transformación tanto de las condiciones de vida de los hombres como, incluso, de la forma de relacionarse entre sí. Sin embargo, también lo hemos visto, esta evolución no solo ha generado efectos positivos, sino que ha propiciado asimismo la aparición de nuevas dificultades y riesgos ${ }^{10}$. Ello ha dado lugar a un generalizado sentimiento contradictorio que se debate entre fiarse de la sabiduría y buena fe de los expertos, o dudar de su capacidad para atisbar y controlar las posibles derivaciones de sus experimentos. ¿Qué hacer entonces para atajar los efectos perniciosos de tales avances, muchos de los cuales obedecen en el fondo

10 Y no exclusivamente en aspectos relacionados con la directa aplicación sobre las personas de los avances biomédicos. La posible propagación deliberada de enfermedades con la finalidad de causar daños o provocar muertes, o el potencial desarrollo de agentes biológicos con unas características raciales o étnicas específicas, o para atacar infraestructuras agrícolas o industriales, son simplemente un par de ejemplos que nos permiten entender hasta donde puede llegar la abusiva y maliciosa utilización de los descubrimientos científicos. MARTÍNEZ MORÁN, Narciso: "Los derechos humanos como límite a la libertad en las investigaciones biomédicas». Op. cit., pp. 66 y 67. 
a tentadores intereses que poco o nada tienen que ver con proteger la vida y la dignidad de las personas? Los revolucionarios adelantos biotecnológicos nos conducen de nuevo al sempiterno interrogante de si puede hacerse todo lo que técnicamente es posible, o si, por el contrario, hay que establecer algún tipo de límite a esta clase de investigaciones. Hoy más que nunca se pone de relieve que los argumentos técnico-científicos no resuelven por sí solos la gran complejidad que encierran las cuestiones aludidas; es preciso acudir, sin más remedio, al análisis filosófico y jurídico. Como dice Ana María Marcos, "necesitamos orientación, sabiduría que nos ayude a corregir los desafueros de la técnica"11. Necesitamos "apelar a la dimensión ética del ser humano, (...); una ética que oriente las conductas de los individuos, eminentemente práctica, y que ponga su empeño en hacerse aplicada" 12 . La investigación es necesaria, qué duda cabe, tanto que podría decirse incluso que el hombre tiene la obligación de no dejar de investigar en las diferentes áreas del conocimiento para mejorar las condiciones de vida en la tierra. Pero, insistimos, no queda más opción que encauzar inteligentemente nuestro insaciable deseo de conocer para evitar así que la ciencia siga siendo hoy, como apuntó el Dr. Diego Gracia, la gran amenaza de la vida humana. De esta forma seremos capaces de dar respuesta a preguntas tales como: ¿hasta dónde es admisible la manipulación de las personas?, ¿qué protección merece el no nacido?, ¿es moralmente aceptable ayudar a morir al enfermo terminal?, ¿cabe admitir la clonación reproductiva?, ¿podemos desarrollar productos que supongan un peligro para el medio ambiente? Son todas ellas cuestiones que exigen sin demora explicación y que en el fondo plantean dilemas de profundo calado como el origen y sentido de la vida, el concepto de muerte, el valor del principio de autonomía del paciente, etc. Y son al mismo tiempo ejemplos, buenos ejemplos, que muestran con meridiana claridad "la trascendencia de los nuevos problemas que han propiciado la emergencia de la bioética como disciplina y el enorme auge que han experimentado las relaciones entre biología, medicina, ética y derecho"13.

Así es, los progresos científicos a los que hacíamos inicialmente mención, con sus luces y sus sombras, es decir, con todos los aspectos positivos que conllevan pero también con las repercusiones más negativas o desfavorables para los derechos más fundamentales

11 MARCOS DEL CANO, Ana María: "La Bioética y el Bioderecho desde los Derechos Humanos". En MARCOS DEL CANO, Ana María (coord.): Bioética y Derechos Humanos. Op. cit., p. 21.

12 Ibídem.

13 Ibídem, p. 19. 
de las personas, dieron lugar ya hace décadas a la aparición de una nueva disciplina, dentro del campo de la ética, que se ocupa, en términos generales, de las cuestiones relativas a la vida en un sentido amplio. Se trata de la bioética. Este término (de bios -vida- y ethos -ética-), como es sobradamente conocido, surge en la década de los setenta del pasado siglo para referirse al inevitable diálogo que debía establecerse entre los avances científicos de la medicina y la biología y los principios y valores éticos ${ }^{14}$. Nace, pues, como indica el profesor Rafael Junquera, con vocación de relacionar dos áreas del saber que se encontraban aisladas entre sí: las ciencias y las humanidades ${ }^{15}$. Sin embargo, las primeras reflexiones que podrían enmarcarse en el ámbito de la bioética tuvieron lugar unos años antes ${ }^{16}$, como consecuencia de una serie de escándalos relacionados con la experimentación en seres humanos. En 1963, por ejemplo, se supo que en un hospital de Brooklyn se habían inyectado células tumorales a pacientes ancianos sin su consentimiento. También salió a la luz el estudio sobre la vacuna contra la hepatitis llevado a cabo en un hospital de Nueva York mediante la inoculación del virus a niños con discapacidad. Y, en fin, es de destacar también que los trabajos del teólogo Paul Ramsey, de finales de los sesenta, fueron de especial importancia en el origen de la bioética en los EE.UU. Empero, dicho término, tal y como hemos señalado, surgió con fuerza en los años setenta al ser utilizado por Van Rensselaer Potter (Profesor de Oncología de la Universidad de Wisconsin) en su artículo titulado Bioethics: the science of survival (1970) y, un año después, en su libro Bioethics. Bridge to the Future. Ahora bien, este autor no lo empleó para designar una rama del saber, sino que lo sugirió como un nuevo espacio de la ética cuyo objeto fuera dar respuesta a los retos planteados por los avances científicos en el terreno de la medicina y la biología. Poco a poco el interés y la reflexión en torno a estas cuestiones fueron en aumento, lo que dio lugar a la aparición de multitud de centros, organismos e instituciones ${ }^{17}$ dedicadas al estudio de los problemas de la vida, la

14 GÓMEZ SÁNCHEZ, Yolanda: "Derechos y deberes de los pacientes”. En GÓMEZ SÁNCHEZ, Yolanda y REBOLLO DELGADO, Lucrecio: Biomedicina y protección de datos. Madrid, Dykinson, 2008, p. 233.

15 JUNQUERA DE ESTÉFANI, Rafael: “El Bioderecho”. En MARCOS DEL CANO, Ana María (coord.): Bioética y Derechos Humanos. Op. cit., p. 120.

16 Aunque como apunta Ana María Marcos, "se puede decir que el término fue acuñado por Fritz Jahr en el año 1927, en el contexto de la búsqueda de la aplicación de la física y la química a los seres vivos en general". MARCOS DEL CANO, Ana María: "La Bioética y el Bioderecho desde los Derechos Humanos". Op. cit., p. 26.

17 De entre los que merece mención especial el Kennedy Institute of Bioethics, creado por el Ginecólogo André Hellegers en la Universidad de Georgetown en 1971. 
medicina y la salud ${ }^{18}$. En definitiva, poco a poco fue configurándose una nueva especialidad, caracterizada, frente a la ética médica anterior, por su carácter secular y racional ${ }^{19}$.

Pero, ¿qué es entonces la bioética?, ¿cómo puede conceptuarse? A nuestro juicio una clara y completa definición de la misma es la que la considera como "el estudio sistemático de la conducta humana en el campo de las ciencias de la vida y del cuidado de la salud, en cuanto que esta conducta es examinada a la luz de los valores y principios morales" 20 . Es decir, el método de la bioética parte del escrutinio detallado y minucioso de las actuaciones que el hombre puede llevar a cabo sobre el hombre gracias a los adelantos médicos y biológicos, y a partir de ahí "infiere las implicaciones antropológicas y éticas que de ellos se derivan y propone aquellas soluciones más acordes con lo que es el hombre y lo que supone un verdadero progreso humano" 21 . Esta tarea, como cabe imaginar, no puede llevarse a cabo únicamente por filósofos, sino que obliga a formar equipos interdisciplinares cuyo trabajo y esfuerzo compartido permita dar respuesta (de manera anticipada, y no a posteriori, cuando ya se ha producido el daño) ${ }^{22}$ al amplio abanico de problemas ético-sociales que genera hoy este sector de la ciencia ${ }^{23}$.

Por tanto, la inicial necesidad de establecer pautas de actuación bajo el formato de principios moralmente vinculantes para los investigadores y demás operadores biomédicos, así como la reticencia de todos ellos a ver regulada su actividad mediante normas jurídicas, fueron factores clave para el surgimiento y extensión de la bioética en un contexto caracterizado por la discrecionalidad en cuanto a qué poder hacer o no en el terreno de la medicina y la biología. Sin embargo, el progresivo aumento en número y complejidad de los problemas generados por los nuevos conocimientos biomédicos demandaron una ordenación de distinta naturaleza; exigieron la intervención del derecho para establecer un corpus normativo cuya capacidad coercitiva no dejase resquicio alguno a una actuación sin

18 MARCOS DEL CANO, Ana María: "La Bioética y el Bioderecho desde los Derechos Humanos". Op. cit., pp. 26 y 27.

19 JUNQUERA DE ESTÉFANI, Rafael: “El Bioderecho”. Op. cit., p. 121.

20 Definición citada por el profesor Rafael Junquera en su trabajo titulado "Los Derechos Humanos en la era de la Biotecnología”. Op. cit., p. 93.

${ }_{21}$ POSTIGO SOLANA, Elena y DÍAZ DE TERÁN VELASCO, M${ }^{\mathrm{a}}$ Cruz: "Nueva eugenesia: la selección de embriones in vitro". En BALLESTEROS LLOMPART, Jesús y APARISI MIRALLES, Ángela: Biotecnología, dignidad y derecho: bases para un diálogo. Barañáin (Navarra), EUNSA, 2004, p. 88.

22 Ibídem, p. 98.

23 CASADO, María: "La Bioética”. En CASADO, María, (ed.): Materiales de Bioética y Derecho. Barcelona, Cedecs, 1996, p. 40. 
límites en un ámbito de la ciencia tan delicado. Surgió de esa manera el bioderecho como aquella consideración normativa, doctrinal y jurisprudencial relativa a las nuevas técnicas sobre la vida humana ${ }^{24}$, siendo elementos que contribuyeron a su emergencia, por un lado, el reconocimiento de la libertad del sujeto para tomar autónomamente aquellas decisiones que pudieran afectar a su salud, a su integridad física o a su bienestar, y, por otro, la urgente "necesidad de dotar de regulación jurídica el resultado derivado de los nuevos avances biotecnológicos"25. El bioderecho nació, pues, como un elemento imprescindible de cara a conseguir que los postulados éticos fuesen verdaderamente respetados desde un punto de vista práctico.

Es evidente entonces, como dice la profesora Yolanda Gómez, que bioética y bioderecho no son la misma $\operatorname{cosa}^{26}$, a pesar de la estrecha línea que les separa. Se trata en efecto de disciplinas distintas pero profundamente interrelacionadas. Según la citada autora, la primera de ellas tiene hoy una misión diferente a la que animó su aparición: su fin último ya no es tanto elaborar un repertorio de principios éticos destinado a los investigadores y operadores biomédicos, sino llevar a cabo una profunda deliberación para conseguir un auténtico consenso bioético que sirva de base para la aprobación de normas jurídicas nacionales e internacionales cuyo objeto sea ofrecer respuestas a problemas de suma importancia para la vida humana ${ }^{27}$. Por su parte, el bioderecho es el instrumento necesario para garantizar la efectiva aplicación de las conclusiones de la bioética ${ }^{28}$, de tal forma que cuanto más sólidos sean los fundamentos de esta, mayor será la capacidad de aquel para conseguir verdadera y plena justicia.

Así pues, vemos como bioética y bioderecho forman un tándem fundamentado en la recíproca dependencia que tiene cada uno de sus elementos respecto del otro. Deben sin más remedio caminar juntos para conseguir que sean de obligado cumplimiento una serie de parámetros morales ampliamente consensuados y capaces de ser aceptados por todos como una ética de mínimos respetuosa con la diversidad ideológica pero protectora sin reservas de los derechos más esenciales de las personas. Este es en el fondo el fin último que

24 JUNQUERA DE ESTÉFANI, Rafael: "Los Derechos Humanos en la era de la Biotecnología”. Op. cit., p. 95.

25 GÓMEZ SÁNCHEZ, Yolanda: "Derechos y deberes de los pacientes". Op. cit., pp. 235 y 236.

26 Ibídem, p. 237.

27 Ibídem.

28 DE MIGUEL BERIAIN, Íñigo: El embrión y la biotecnología. Un análisis éticojurídico. Op. cit. p. 64. 
deben perseguir tales áreas del conocimiento: servir de medio para el establecimiento de límites a los avances en el terreno de las ciencias biomédicas ${ }^{29}$, límites cuya base serán, como veremos, los derechos humanos, pero que dependerán, a fin de cuentas, de qué entendamos por ser humano y de qué valor atribuyamos a su vida.

\section{SER HUMANO: SER DIGNO}

\subsection{Introducción}

En efecto, los progresos biomédicos nos obligan sin más remedio a replantearnos las eternas preguntas a las que acabamos de hacer mención. Como dice Roberto Andorno, y sin duda alguna así es, la solución a todos los problemas que derivan de tales avances pasa por las respuestas que demos a dichos interrogantes ${ }^{30}$. Sin llegar hasta las entrañas de este misterio no seremos capaces de ofrecer soluciones sólidas y justas para las actuaciones que propone el imparable desarrollo de la ciencia. No debemos olvidar que lo que está en juego es la esencia misma del hombre, la cual parece que pidiera a gritos una muy profunda reflexión filosófica acerca de sí misma para evitar la cosificación del ser humano.

Sin entrar ahora, como es normal, en un estudio exhaustivo de cada una de las cuestiones planteadas, cabe decir que un ser humano es un ser cuya naturaleza o esencia es biológica y ontológicamente humana. Lo es desde el mismo momento en que comienza el proceso embrionario, de tal forma que con la fecundación surge un nuevo ser distinto de todos los que han existido, existen y existirán. Incluso aunque pudiera opinarse que en la primera fase de dicho proceso no existe aún persona humana, sin embargo, nos encontramos, ya desde el comienzo del mismo, por lo menos con una individualidad genética (distinta y diferenciada de la de los padres) intrínsecamente orientada a la constitución de una persona. Por tanto, desde un punto de vista biológico, y a pesar de su estrecha relación con la madre, el embrión no es una parte de aquella sino un organismo au-

29 Denominación utilizada por el profesor Romeo Casabona para incluir en ella "la Medicina, la Biología y otras ciencias afines que tienen como objeto de estudio la vida y la salud del ser humano, tanto en cuanto permiten explicar la primera en su origen y en su final como cuando inciden en cualquier fase del proceso natural de ambas". ROMEO CASABONA, Carlos María: El Derecho y la Bioética ante los límites de la vida humana. Madrid, Centro de Estudios Ramón Areces, 1994, p. 3.

30 ANDORNO, Roberto: Bioética y dignidad de la persona. Madrid, Tecnos, 2012, p. 67.

(C) UNED. Revista de Derecho UNED, núm. 27, 2021 
tónomo que se rige por sí mismo. Es, pues, científicamente indiscutible que la vida humana comienza en el instante de la fecundación.

Mucho más claro aún resulta entender que la fecundación origina auténtica vida humana si atendemos a los hitos más significativos del proceso embrionario. Así, debe destacarse que en las cuatro primeras semanas de desarrollo del embrión el nuevo ser presenta una forma alargada: se ha formado su apéndice cefálico, existe un rudimento de los ojos, del corazón, del hígado y de la columna vertebral $^{31}$. Incluso antes de completarse la formación del sistema nervioso central, el embrión será capaz de responder a ciertos estímulos, aunque la capacidad de movimiento no llegará hasta las seis semanas. A partir de la quinta, siendo su tamaño inferior a un centímetro, es perceptible el corazón y los aparatos respiratorio, gastroentérico y genitourinario ${ }^{32}$. Al concluir la séptima semana, la forma corpórea del embrión está claramente definida. En la octava, ya de tres centímetros, el nuevo ser responderá a estímulos externos, moviendo ligeramente las extremidades y doblando incluso el cuello. Además, en esta fase del desarrollo surge también la actividad cerebral legible. A las doce semanas de la gestación, con un tamaño ya de doce centímetros, el ser en formación habrá desarrollado la deglución y su estructura cerebral estará culminada. A partir de aquí deja de considerarse embrión y pasa a denominarse feto.

\subsection{La dignidad del ser humano}

Pero, como antes decíamos, la persona se define también por su componente ontológica, aspecto este que nos conduce directamente al estudio de la dignidad del ser humano. Se trata de una materia verdaderamente apasionante que constituye hoy día uno de los temas centrales de la ciencia en general y del derecho en particular. Dentro de esta parcela del conocimiento encontramos un sin fin de textos normativos en los que aparecen reconocidos los derechos fundamentales del hombre y la dignidad de la persona como núcleo de todos ellos. Sin embargo, curiosamente, a pesar de tan generalizado reconocimiento lo que no aparece es la razón de ser última de estos derechos, o, si se prefiere, las razones trascendentes sobre las que se sustenta su existencia. Como afirma el profesor Jesús González, da la impresión de que existen "porque así lo han decidido los votos mayo-

31 LASANTA, Pedro Jesús: Abortar, ¿es justo?, ¿es bueno?... Logroño, Horizonte, 2009, p. 22.

32 DE MIGUEL BERIAIN, Íñigo: El embrión y la biotecnología. Un análisis éticojurídico. Op. cit. p. 14. 
ritarios de los representantes de los Estados en un organismo internacional, o de los miembros de un Parlamento"33. Parece que se recogen una y otra vez, especialmente en las declaraciones y convenios internacionales, sin pararse a pensar en las razones de fondo que justifican ese reconocimiento añadido; dejando a un lado, quizá intencionadamente, el comprometido debate acerca de su fundamento.

Por otra parte, en muchas ocasiones se emplea la noción de dignidad de una manera abusiva, reiterativa, e, incluso, de forma puramente retórica ${ }^{34}$, como si ella pudiera resolver por sí sola la mayoría de los dilemas de índole moral que surgen continuamente en el transcurrir de la vida. En nombre de la dignidad se llega a menudo a soluciones radicalmente contrarias, extrayendo cada uno de los implicados conclusiones prácticas completamente diferentes ${ }^{35}$ sobre temas de tanta trascendencia como el aborto, la eutanasia, las manipulaciones genéticas o la experimentación médica sobre las personas $^{36}$. Y no es extraño que todo esto suceda si tenemos en cuenta los múltiples significados que se atribuyen a la palabra dignidad. Dignidad significa excelencia, eminencia, grandeza, honor, respetabilidad; significa ser distinguido, ilustre, insigne, etc. Pero esta manera de entender la dignidad alude claramente a la perspectiva ética de la misma, ya que se asocia a la forma de comportarse y de ser desde un punto de vista práctico, o se asimila a la importante situación social que ostentan determinadas personas. En consecuencia, es obvio que en este sentido unas personas son más dignas que otras en función de su grandeza o del rol que desempeñan en la sociedad. Sin embargo, como ahora veremos, la dignidad también se refiere a un aspecto intrínseco del ser humano, aspecto que no depende en absoluto del ejercicio de sus actos ${ }^{37}$. Por tanto, resulta preciso preguntarse por el concepto y, desde luego, por el fundamento último de la dignidad; solo así podrá "encontrarse un baluarte inexpugnable en que el hombre se sienta seguro frente a todo y frente a todos"38.

33 GONZÁLEZ PÉREZ, Jesús: La dignidad de la persona. Madrid, Civitas, 1986, p. 19.

34 ANDORNO, Roberto: Bioética y dignidad de la persona. Op. cit., p. 37.

35 GONZÁLEZ, Ana Marta: "La dignidad de la persona, presupuesto de la investigación científica”. En BALLESTEROS LLOMPART, Jesús y APARISI MIRALLES, Ángela: Biotecnología, dignidad y derecho: bases para un diálogo. Op. cit., p. 18.

36 Siguiendo el ejemplo que pone Ana Marta González, algunos justifican la eutanasia como "el derecho a morir dignamente", mientras que para otros dicha práctica comporta "la abdicación de la propia dignidad humana”. Ibídem.

37 MARTÍNEZ MORÁN, Narciso: "Los derechos humanos como límite a la libertad en las investigaciones biomédicas». Op. cit., pp. 74 y 75 .

38 GONZÁLEZ PÉREZ, Jesús: La dignidad de la persona. Op. cit., p. 20. 
Para centrar la cuestión, lo primero que tenemos que hacer es aclarar brevemente la diferencia entre las expresiones dignidad ontológica y dignidad moral. La dignidad ontológica tiene, digamos, un carácter fundante, esto es, acompaña a todo ser humano por el mero hecho de serlo, por la sencilla razón de estar dotado de una incuestionable naturaleza racional. La dignidad ontológica forma parte de la persona por ser cualitativamente distinta del resto de entes que pueblan el universo ${ }^{39}$. Desde este punto de vista, la dignidad debe ser considerada como la fuente de todos los derechos. En cambio, la dignidad moral, a diferencia de la anterior, no hace referencia al ser sino al obrar ${ }^{40}$. Depende del propio comportamiento de cada persona, de cómo esta ejercite su libertad en cada momento; en definitiva, de si actúa de manera inmoral o si lo hace a la altura de lo que reclama su dignidad ontológica ${ }^{41}$. Y esta, sobre la que nosotros debemos dirigir ahora nuestra atención, ha representado desde tiempos pretéritos un valor absoluto e incondicional, lo que significa que bajo ninguna circunstancia podemos someter a un ser humano a un trato vejatorio o degradante, a pesar de que sus actos pudieran ser profundamente indignos.

En efecto, ya los antiguos griegos comparaban el alma con un espejo donde se podía percibir un reflejo auténtico de la divinidad; la veían como el lugar de encuentro entre lo humano y lo divino ${ }^{42}$, idea que de alguna forma se mantuvo con el pensamiento estoico ${ }^{43}$. El cristianismo, en cambio, difunde la convicción de que el hombre está hecho a imagen y semejanza de Dios ${ }^{44}$ : cada alma es una obra maestra del Creador; dotación trascendente de todo ser humano de la que deriva el superior valor de esta clase de vida, y cuyo fin último consiste en orientarse hacia aquel para tener una existencia bienaventurada y gozosa ${ }^{45}$. Tal esencia especialísima y única es la que

39 MARTÍNEZ MORÁN, Narciso: "Los derechos humanos como límite a la libertad en las investigaciones biomédicas». Op. cit., p. 77.

40 Ibídem.

41 GONZÁLEZ, Ana Marta: "La dignidad de la persona, presupuesto de la investigación científica". Op. cit., pp. 31 a 41.

42 ANDORNO, Roberto: Bioética y dignidad de la persona. Op. cit., p. 75.

43 Así, la noción de dignidad es presentada por Cicerón como el carácter distintivo del ser humano respecto de los animales. Según él, este principio constituye el punto de partida necesario de cualquier reflexión ética. Ibídem.

${ }_{44}$ GONZÁLEZ, Ana Marta: "La dignidad de la persona, presupuesto de la investigación científica”. Op. cit., p 27.

45 No obstante, a finales del XVIII el pensamiento racionalista aspira a reemplazar las bases trascendentes surgidas del cristianismo por un fundamento sin referencia alguna a nociones metafísicas como las de Dios y alma. Esta postura, como dice Roberto Andorno, conduce a diluir el valor de la dignidad del ser humano: 
hace que el hombre esté dotado de dignidad; una específica y suprema cualidad solo a él atribuible por cuya virtud se erige como superior a todo lo demás que habita la tierra. Se trata, como decimos, de un principio absoluto e inderogable que implica que no se puede instrumentalizar jamás a un ser humano, esto es, tratarlo como un mero objeto ${ }^{46}$. Sea cual sea el estado de desarrollo en el que se encuentre ese ser, la dignidad, que es consustancial al mismo, impone inexorablemente la máxima protección para sus derechos más básicos y esenciales, y muy particularmente para su derecho a la vida. Por tanto, a partir de aquí solo es posible afirmar que la vida humana es sagrada, lo que se traduce en que debe ser respetada en todo momento y bajo cualquier circunstancia, independientemente de que atribuyamos o no a la misma personalidad (asunto extremadamente complejo que nos conduce a un debate, el de ser humano vs persona, condenado sin remedio al desacuerdo por las diversas definiciones que se mantienen del concepto persona y por la carga ideológica que hay detrás de cada postura $\left.{ }^{47}\right)$. No obstante, no po-

¿cómo puede el hombre -se pregunta- merecer un respeto absoluto si está privado de todo vínculo con lo absoluto? ANDORNO, Roberto: Bioética y dignidad de la persona. Op. cit., p. 76.

46 Somos plenamente conscientes de que este intento de dar una definición-explicación de la dignidad humana puede que no pase precisamente de eso, de ser un mero intento. Decimos esto porque, como afirma Roberto Andorno, la dignidad humana es difícilmente definible, hasta el punto que, como nos recuerda el autor, ningún instrumento jurídico internacional se ha atrevido a ofrecer un concepto de la misma. Ello se debe a que "estamos ante una noción que carga con el peso de una larguísima tradición filosófica y cuya justificación última ha sido explicada de diversos modos a lo largo de la historia, (...). A la disparidad filosófica se agrega el obstáculo de la diversidad cultural, es decir, el hecho de que toda definición de una noción tan básica está condicionada en buena medida por factores culturales. Es por ello que los instrumentos internacionales (...) evitan definir la dignidad humana y prefieren dejar librada la determinación de su significado a la intuición común y, en última instancia, al criterio de los tribunales en los casos concretos que se sometan a su decisión". ANDORNO, Roberto: "La dignidad humana como fundamento de la Bioética y de los Derechos Humanos en la Declaración Universal". En GROS ESPIELL, Héctor y GÓMEZ SÁNCHEZ, Yolanda (coords.): La Declaración Universal sobre Bioética y Derechos Humanos de la UNESCO. Granada, Comares, 2006, p. 257. No obstante, el propio Roberto Andorno nos dice que "la idea de dignidad (...) hace referencia al valor único e incondicional que tiene la existencia misma de todo ser humano, independientemente de la edad, salud física o mental, origen étnico, sexo, condición social o económica o religión del individuo en cuestión. Es su condición humana como tal la que genera un deber de respeto hacia su persona". Ibídem, p. 258. Afirma además que "la dignidad es en buena medida una realidad prejurídica, que precede y da fundamento al orden jurídico en su conjunto”. Ibídem.

47 En el centro de este debate se encuentran los conceptos de persona y ser humano, si bien es cierto que este último no genera grandes discrepancias; la verdadera problemática reside en el otro, en el de persona. Así, con carácter general, cabe decir que son dos las posturas en las que podemos agrupar los diferentes planteamientos doctrinales: por un lado están aquellos que consideran que ambos térmi- 
demos dejar de reconocer que hay situaciones muy excepcionales ${ }^{48}$ para las cuales hay que encontrar soluciones coherentes y sensatas, pero que en modo alguno tienen que implicar echar por tierra el principio profundamente humano de la santidad de la vida.

Dicho esto, estamos en condiciones de afirmar que el fundamento de la dignidad ${ }^{49}$ de la persona, de toda persona humana y

nos son similares, y, por otro, hay una gran diversidad de teorías que defienden que persona y ser humano no es lo mismo. Los que mantienen la equivalencia de tales expresiones opinan que es la continuidad biológica entre el cigoto y el ser humano adulto la clave para justificar la personalidad $a b$ initio. Es decir, el ser humano es persona desde el momento de la fecundación, aun cuando no haya desarrollado todas sus capacidades, y, en consecuencia, exige el reconocimiento de todos los derechos inherentes a su dignidad. En cambio, los defensores de la postura contraria niegan la personalidad del embrión, ya sea en todo momento o en los primeros estadios de su existencia. Los motivos aducidos en este caso son, básicamente, la falta de individualidad y la falta de racionalidad. En cuanto al primero de tales motivos, sostienen un considerable número de autores que la posible disociación del huevo fecundado (que producirá la gemelación del embrión) o su unión a otros embriones para crear un único individuo, así como la misma totipotencia de las células embrionarias antes de su implantación, son circunstancias todas ellas que ponen en entredicho el postulado de la individualidad del embrión durante los primeros catorce días desde la fecundación. Consecuentemente, no puede ser considerado persona pues carece de las propiedades de ser uno solo y de ser único. Por otra parte, respecto de los que aducen falta de racionalidad en el embrión, son variados los argumentos que se usan. Por ejemplo, uno de ellos es el denominado de la autoconciencia o de la identidad personal, que agrupa a su vez diferentes tesis y que considera que para que un ser humano sea persona tiene que haber desarrollado una serie de capacidades de índole intelectual (las cuales varían dependiendo del autor: funciones cerebrales concretas, la simple captación de la señal de actividad cerebral por el electroencefalograma, la aparición de la estría primitiva, etc.). Así, para los defensores de estas teorías podrá considerarse persona al ser humano que posee identidad, esto es, que puede identificarse a sí mismo o ser identificado por otros. DE MIGUEL BERIAIN, Íñigo: El embrión y la biotecnología. Un análisis ético-jurídico. Op. cit., pp. 68 y ss.

48 El caso, por ejemplo, de las molas hidatiformes. Se trata de un tumor producido por una degeneración del tejido placentario, esto es, un tumor que tiene su origen en una fecundación en la que la mezcla del material cromosómico genera un cáncer. Se caracteriza por un desarrollo anormal de la placenta, adquiriendo la forma de masa de pequeñas vesículas reunidas por filamentos, formando una figura parecida a un racimo de uvas. DE MIGUEL BERIAIN, Íñigo: El embrión y la biotecnología. Un análisis ético-jurídico. Op. cit. p. 170. Para los defensores de la llamada postura clásica (los que defienden la equivalencia entre ser humano y persona) la mola humana es una persona. Nosotros no entramos en tal disquisición. La mola, como cualquier otro fruto de la concepción, es ser humano, es decir, es un nuevo ser (en tanto que es) con una composición humana. No obstante, sus características tan sumamente particulares y excepcionales obligan sin duda a conferirle un trato distinto al que debe recibir el resultado de la fecundación que es apto para evolucionar sin problemas.

49 La cual sirve a su vez de fundamento de todo ordenamiento jurídico, hasta el punto de que la violación de algunos derechos fundamentales supone atentar directamente contra la dignidad humana. 
solo de ella ${ }^{50}$, reside en su naturaleza de origen divino ${ }^{51}$ que le hace gozar de una grandeza infinita e indescriptible, que le hace ser perfecta y sublime expresión encarnada de nuestro Creador. En consecuencia, es fácil inferir que esta esencia propia del ser humano, maravillosa y misteriosa, obliga a que cualquier miembro de nuestra especie sea tratado con el máximo respeto y, por qué no decirlo, con el profundo y verdadero amor que es capaz de dar todo hombre por la gracia de Dios. Por tanto, la dignidad, cualidad constitutiva del hombre, corolario directo de su condición espiritual, impide cualquier trato inhumano o degradante para cualquier persona. De la dignidad deriva el derecho a la vida de todo ser humano, lo cual es extensible a cualquier investigación biomédica que resulte negativa o que atente contra aquel.

Así pues, los límites éticos y jurídicos que se impongan a los avances biotecnológicos tendrán como fin último la salvaguarda de lo más íntimo y exclusivo del hombre: su dignidad. Frente a las posturas relativistas, el pensamiento cristiano sitúa al espíritu de cada hombre en lo más alto, señalando, a partir del mismo, la universalidad de la dignidad humana ${ }^{52}$, la cual se erige a su vez como fundamento de los derechos humanos (que igualmente son universales por tener a la dignidad como su razón de ser última). Por tanto, si la base de tales derechos es la dignidad del hombre, la mejor manera de defenderla de los efectos perniciosos de los progresos de las ciencias biomédicas (como ante cualquier otra circunstancia por la que pudiera resultar amenazada), será estableciendo límites cuya referencia sean aquellos derechos.

\section{LÍMITES A LA LIBERTAD DE INVESTIGACIÓN}

Según hemos ido viendo en los puntos precedentes, la actividad investigadora tiene una doble cualidad: por un lado, es el motor que impulsa el desarrollo de las sociedades, que permite mejorar la calidad y las condiciones de vida del hombre; por otro, y al mismo tiempo, puede generar enormes males si no se lleva a cabo

50 Dice Ana Marta González que "cuando hablamos de afirmar la dignidad humana no hablamos de la dignidad en general -que no es más que una idea abstractasino de los hombres concretos: son ellos (...) los que son dignos: los que con su sola presencia demandan de los demás un trato respetuoso" GONZÁLEZ, Ana Marta: "La dignidad de la persona, presupuesto de la investigación científica”. Op. cit., p. 22.

51 GONZÁLEZ PÉREZ, Jesús: La dignidad de la persona. Op. cit., pp. 26 a 30.

52 BALLESTEROS LLOMPART, Jesús: "Exigencias de la dignidad humana en la Biojurídica”. En BALLESTEROS LLOMPART, Jesús y APARISI MIRALLES, Ángela: Biotecnología, dignidad y derecho: bases para un diálogo. Op. cit., pp. 62 y 63.

(C) UNED. Revista de Derecho UNED, núm. 27, 2021 
con la prudencia debida y con la necesaria independencia respecto de aquellos que financian las diferentes líneas de investigación. En este último sentido, es claro que la dignidad del ser humano correrá un grave peligro si la ciencia trabaja al servicio de intereses exclusivamente políticos, económicos o de cualquier otra índole tras de los cuales se escondan objetivos alejados por completo de velar por los aspectos más esenciales de la persona. Lo lamentable es que en muchas ocasiones sucede así, desvirtuándose el fin último que debe perseguir la investigación científica, poniéndose esta al servicio de pretensiones espurias que solo miran a la cuenta de resultados. Por si fuera poco con la presión que insuflan los que pagan, un buen número de investigadores del ámbito de la biología y la medicina llevan a cabo actividades a todas luces inmorales, actividades con las que se desprecian los principios éticos más elementales y que solo sirven para deshumanizar el mundo y para poner en evidencia el deseo de ser semidioses de aquellos que las realizan. Afortunadamente, muchos miembros de la comunidad científica no están del lado de dichas prácticas, y demandan respuestas a los múltiples interrogantes éticos y jurídicos que suscitan los adelantos biomédicos. En suma, estos científicos comprometidos con el verdadero progreso del hombre, en un sentido profundamente humano, reclaman el establecimiento de pautas y condiciones de actuación para poder desarrollar con garantías el derecho que tienen a la libertad de investigación.

Como nos recuerda el profesor Martínez Morán, la libertad de investigación es un derecho fundamental que aparece expresamente reconocido en la Declaración Universal de Derechos Humanos (art. 19), texto normativo que contempla asimismo el derecho de toda persona "a participar en el progreso científico y en los beneficios que de él resulten" (art. 27.1). Además, el derecho a la libertad de investigación figura en el resto de declaraciones de derechos y de constituciones democráticas, como sucede por ejemplo con la Constitución Española, que lo recoge dentro del apartado $1^{\circ}$ de su art. $20^{53}$. Ahora bien, como cualquier otro derecho, también el de la libertad de investigación debe ser limitado si por medio de su ejercicio se corre el riesgo de atentar contra otros derechos fundamentales o contra la dignidad del ser humano. En este sentido, nuestra Carta Magna establece en el art. 20.4 que las libertades reconocidas en dicho precepto "tienen su límite en el respeto a los derechos reconocidos en este Título, en los preceptos de las leyes que lo desarrollen y, especialmente

53 MARTÍNEZ MORÁN, Narciso: "Los derechos humanos como límite a la libertad en las investigaciones biomédicas». Op. cit., pp. 85 y 86 . 
en el derecho al honor, a la intimidad, a la propia imagen (...)"54. Teniendo en cuenta el terreno en el que nos movemos, es obligado detenerse en la Declaración Universal sobre el Genoma Humano y los Derechos Humanos ${ }^{55}$, documento que aunque referido específicamente al genoma humano, contiene diversas disposiciones que ayudan a comprender en términos genéricos el alcance del derecho a la libertad de investigación respecto del resto de derechos fundamentales y de la dignidad del hombre ${ }^{56}$. Así, ya su preámbulo insiste en la necesidad de promover la reflexión ética a fin de poner freno a los posibles efectos perniciosos de los progresos científicos en el campo de la biología y la genética. Por su parte, su articulado establece que la investigación se orientará siempre en beneficio de la salud (principio de beneficencia), con pleno respeto a los derechos humanos (art. 5.d)), y que nadie será discriminado por sus características genéticas (art. 6). En cuanto a las investigaciones sobre el genoma humano, impone la obligación de respetar los derechos humanos y la dignidad humana en todas las investigaciones biomédicas (Apartado C, arts. 10, 11 y 12). Y, en fin, el Apartado D fija las condiciones en que debe llevarse a cabo la actividad científica, disponiendo en su art. 13 que "Las consecuencias éticas y sociales de las investigaciones sobre el genoma humano imponen a los investigadores responsabilidades especiales de rigor, prudencia, probidad intelectual e integridad, tanto en la realización de sus investigaciones como en la presentación y utilización de los resultados de éstas (...)".

En resumidas cuentas, lo anterior pone de manifiesto que la investigación no puede conllevar en modo alguno la violación de otros derechos fundamentales, siendo aquí precisamente cuando debe intervenir el Estado fijando límites y condiciones. Ello es debido a que los derechos fundamentales, como hemos visto, tienen su razón de ser en la propia dignidad del hombre ${ }^{57}$, es decir, tratan de proteger aspectos esenciales de su existencia para garantizar que la misma

54 Ibídem, p. 89.

55 Aunque también otros textos internacionales se ocupan de la protección de los derechos humanos y de la dignidad del hombre con respecto a las aplicaciones biomédicas, como por ejemplo el Convenio Europeo para la protección de los Derechos Humanos y la dignidad del ser humano y la Carta Europa de Derechos Fundamentales. Ibídem, p. 91.

56 Nos apoyamos también para desarrollar esta idea en el trabajo recién citado del profesor Martínez Morán. Ibídem, pp. 89 y 90.

57 Hasta el punto de que, como bien señala Javier Blázquez, para protegerla los derechos humanos han ido variando y enriqueciéndose en su contenido a un ritmo perfectamente acompasado con el devenir histórico de cada época. BLÁZQUEZ RUIZ, Javier: Derechos Humanos y Proyecto Genoma Humano. Granada, Comares, 1999, p. 7. 
discurra de forma digna. Los deslumbrantes avances en el terreno de las ciencias biomédicas nos obligan imperiosamente a contar con unos principios o valores que puedan ser generalmente aceptados como patrón de contraste de la corrección o incorrección de dichos progresos, principios que sin duda se encuentran en la base axiológica de los derechos humanos ${ }^{58}$. De esta manera, la dignidad humana será respetada si son respetados todos los derechos humanos, por lo que éstos se erigen como criterio orientador de la bioética y del bioderecho ${ }^{59}$, como los auténticos protagonistas "en las tareas de mediación ética de las prácticas biotecnológicas" ${ }^{60}$. ¿Y por qué nos sirven precisamente tales derechos para cumplir esta función limitadora de dichos adelantos? Según el profesor Benito de Castro, principalmente por dos motivos: en primer lugar, porque los mismos son "descendientes directos, herederos legítimos y mensajeros cualificados de la Justicia". En segundo término, "porque estos derechos han llegado a ser proclamados y están siendo aplicados ya en forma mayoritaria como compendio exponencial del único código ético, jurídico y político que tiene posibilidades reales de lograr una vigencia tendencialmente universal" 61 .

Por tanto, queda claro que los derechos humanos actúan como guardianes de la dignidad del hombre, como el mejor instrumento de que disponemos hoy por hoy para protegerla por constituir el más alto referente del valor único e incondicional que tiene su vida $^{62}$. La vulneración de aquellos derechos supondrá entonces un atentado contra la dignidad, por lo que debemos preguntarnos cuáles de ellos pueden verse violentados por las aplicaciones biotecnológicas. Lo cierto es que la respuesta no es sencilla, y en último extremo siempre dependerá del uso que se haga de tales recursos por parte de los expertos y demás agentes que puedan ponerlos en práctica. No obstante, cabe apuntar de manera abreviada que los referidos adelantos afectan de modo peculiar a los siguientes bienes básicos de la persona ${ }^{63}$ :

58 DE CASTRO CID, Benito: "Biotecnología y derechos humanos: ¿complementariedad o conflicto?”. En MARCOS DEL CANO, Ana María (coord.): Bioética, Filosofía y Derecho. Melilla, UNED-Melilla (Revista Aldaba, no 32), 2004, pp. 14 a 16.

59 MARTÍNEZ MORÁN, Narciso: "Los derechos humanos como límite a la libertad en las investigaciones biomédicas». Op. cit., p. 73.

60 DE CASTRO CID, Benito: “Derechos Humanos. Biotecnología. Derechos Humanos: una compleja interacción circular". Op. cit., p. 47.

61 Ibídem, pp. 52 y 53.

62 ANDORNO, Roberto: "La dignidad humana como fundamento de la Bioética y de los Derechos Humanos en la Declaración Universal”. Op. cit., p. 258.

63 JUNQUERA DE ESTÉFANI, Rafael: "Los Derechos Humanos en la era de la Biotecnología”. Op. cit., pp. 102 y 103. 
a) A la vida. Las técnicas con las que contamos permiten generar vida en un laboratorio, alterar el cuerpo humano o nuestra descendencia, influir sobre nuestra salud.

b) A la libertad. Los últimos descubrimientos nos dan la posibilidad de elegir las características que queremos que tengan nuestros hijos, o de combinar diferentes razas de animales o especies vegetales para crear las que mejor respondan a nuestras necesidades. Y en un sentido opuesto, ello nos conduce a coartar la libertad de las generaciones futuras.

c) A la intimidad. Los progresos biomédicos nos capacitan para obtener mayor información sobre los sujetos, lo que puede generar discriminaciones en diversos ámbitos de la vida (como por ejemplo, a la hora de optar por un puesto de trabajo o de querer contratar un seguro de vida).

d) A la identidad. Las características particulares de cada persona nos hacen ser únicos frente a cualquier otro. Por ello, nuestra identidad puede verse atacada como consecuencia de la información que resulta de los conocimientos en el campo de la genética.

En todo caso, lo que sí es claro es que la dignidad humana se presenta como el límite fundamental a las investigaciones en el campo de las ciencias biomédicas. Es vista incluso como "una suerte de última barrera frente a la amenaza de la alteración de características básicas del género humano que podrían resultar de ciertos desarrollos biotecnológicos, tales como la clonación reproductiva o las intervenciones en la línea germinal" ${ }^{4}$. En estos supuestos, la referencia a los derechos humanos puede ser insuficiente pues los mismos se refieren a individuos o a grupos humanos ya existentes, de tal manera que el que no existe no cuenta con ningún derecho. Como estas técnicas afectan principalmente a la especie humana en su conjunto (incluidas las generaciones futuras), y no a sujetos individualmente considerados, la dignidad resulta ser un argumento idóneo para prevenir de un abuso desmesurado de los poderes biotecnológicos ${ }^{65}$.

Sabiendo entonces que lo que queremos proteger es la dignidad del ser humano, el problema será establecer las condiciones que permitan desarrollar determinadas prácticas sin atentar al mismo

64 ANDORNO, Roberto: "La dignidad humana como fundamento de la Bioética y de los Derechos Humanos en la Declaración Universal”. Op. cit., p. 256.

65 Ibídem. 
tiempo contra aquello que es innegociable desde el punto de vista de la experimentación. En este sentido, hoy hay amplio consenso en que deben exigirse los siguientes requisitos éticos a la investigación clínica $\left.{ }^{66}: 1\right)$ valor social o científico, esto es, deben contribuir a mejorar la salud o el bienestar social; 2) validez científica, lo que significa seguir un metodología rigurosa y acreditada; 3) selección equitativa de la muestra de los sujetos, a fin de distribuir los riesgos de la investigación; 4) relación riesgo/beneficio favorable, de tal forma que los beneficios superen a los riesgos; 5) revisión independiente por parte de una autoridad pública; 6) pleno respeto a los derechos fundamentales de los sujetos directa o potencialmente implicados; y 7) consentimiento informado de las personas que participen en la investigación.

Pero si el respeto a estos criterios resulta primordial, no menos importante es resaltar que las condiciones concretas para cada tipo de práctica o proceso de experimentación deberían ser fijadas desde instancias internacionales por medio del diálogo y el consenso $^{67}$. Lo que está en juego son los aspectos más esenciales de la vida de los seres humanos; más aún, lo que nos jugamos es la integridad misma de nuestra especie, y esto no puede quedar en manos simplemente de aquellos que en un momento dado dirigen los designios de cada uno de los Estados. Las pautas de actuación deben ser únicas e iguales para todos pues todos (los que estamos ahora y los que vengan en un futuro) estamos afectados o podemos estarlo de la misma manera. Aquí no cuentan las fronteras ni las razas ni las opciones políticas. Aquí lo que cuenta es que la ambigüedad del progreso científico nos amenaza a todos con la misma intensidad, y es por ello que desde el respeto a la pluralidad de opciones morales que caracteriza a las sociedades actuales, debe fijarse un código común que constituya un marco de acuerdo por medio del cual todas las personas puedan considerarse ligadas por una misma estructura que permita la resolución de los conflictos generados por los adelantos biotecnológicos ${ }^{68}$.

${ }^{66}$ Los exponemos tal y como los recoge el profesor Martínez Morán en su trabajo "Los derechos humanos como límite a la libertad en las investigaciones biomédicas». Op. cit., p. 92.

67 Ibídem, pp. 93 y 94.

68 CASADO, María: "Bioética y Derecho". En GROS ESPIELL, Héctor y GÓMEZ SÁNCHEZ, Yolanda (coords.): La Declaración Universal sobre Bioética y Derechos Humanos de la UNESCO. Op. cit., p. 36. 


\section{CONCLUSIÓN FINAL}

Por tanto, concluyendo, es el momento de poner al servicio del hombre el mejor conocimiento del hombre, de recuperar su dimensión filosófico-sapiencial ${ }^{69}$ para defender nuestra dignidad ante los efectos negativos que genera el desarrollo en el campo de las ciencias biomédicas. Tenemos sabiduría y capacidad suficiente para ponernos de acuerdo, cualidades, como otras muchas, que deben emplearse en favor del bien común. El descubrimiento de las verdades que esconden los arcanos de la naturaleza debe permitirnos embelesarnos con la contemplación de las esencias ocultas en cuanto nos rodea. Y es precisamente la que define al ser humano, la que nos muestra su misteriosa y maravillosa infinitud, la que tiene que perseguir con más ahínco el arte de hacer ciencia. Eso y, repetimos, una vez sabedores de la grandeza que encierra nuestro ser, trabajar sin descanso para no dejar que unos cuantos consigan imponer prácticas cuyas consecuencias sobre nosotros pueden ser irreparables. Como dice Ana Marta González, el conocimiento pierde su sentido más profundo si no sirve para afirmar la dignidad del hombre $^{70}$, si no es usado para que la ciencia y la tecnología nos lleven hacia un verdadero progreso humano. En ello debemos poner nuestro empeño: sabiduría para conocernos; conocimiento y consenso para respetarnos.

\section{BIBLIOGRAFÍA}

Andorno, Roberto: Bioética y dignidad de la persona. Madrid, Tecnos, 2012.

ANDORNo, RoBerto: "La dignidad humana como fundamento de la Bioética y de los Derechos Humanos en la Declaración Universal". En GROS ESPIELL, Héctor y GÓMEZ SÁNCHEZ, Yolanda (coords.): La Declaración Universal sobre Bioética y Derechos Humanos de la UNESCO. Granada, Comares, 2006.

Ballesteros LlOMPart, Jesús: "Exigencias de la dignidad humana en la Biojurídica”. En BALLESTEROS LLOMPART, Jesús y APARISI MIRALLES, Ángela: Biotecnología, dignidad y derecho: bases para un diálogo. Barañáin (Navarra), EUNSA, 2004.

69 POSTIGO SOLANA, Elena y DÍAZ DE TERÁN VELASCO, Mª Cruz: "Nueva eugenesia: la selección de embriones in vitro". Op. cit., p. 98.

70 GONZÁLEZ, Ana Marta: "La dignidad de la persona, presupuesto de la investigación científica”. Op. cit., p. 20. 
Blázquez Ruiz, Javier: Derechos Humanos y Proyecto Genoma Humano. Granada, Comares, 1999.

Casado, María: "Bioética y Derecho". En GROS ESPIELL, Héctor y GÓMEZ SÁNCHEZ, Yolanda (coords.): La Declaración Universal sobre Bioética y Derechos Humanos de la UNESCO. Granada, Comares, 2006.

CASAdo, María: "La Bioética”. En CASADO, María, (ed.): Materiales de Bioética y Derecho. Barcelona, Cedecs, 1996.

De Castro Cid, Benito: "Biotecnología y derechos humanos: ¿complementariedad o conflicto?”. En MARCOS DEL CANO, Ana María (coord.): Bioética, Filosofía y Derecho. Melilla, UNED-Melilla (Revista Aldaba, $\mathrm{n}^{\circ}$ 32), 2004.

De Castro Cid, Benito: "Derechos Humanos. Biotecnología. Derechos Humanos: una compleja interacción circular". En MARCOS DEL CANO, Ana María (coord.): Bioética y Derechos Humanos. Madrid, UNED, 2011.

De Miguel Beriain, Íñigo: El embrión y la biotecnología. Un análisis ético-jurídico. Granada, Comares, 2004.

Gómez Sánchez, Yolanda: "Derechos y deberes de los pacientes". En GÓMEZ SÁNCHEZ, Yolanda y REBOLLO DELGADO, Lucrecio: Biomedicina y protección de datos. Madrid, Dykinson, 2008.

GonzÁLEZ, ANA MARTA: "La dignidad de la persona, presupuesto de la investigación científica". En BALLESTEROS LLOMPART, Jesús y APARISI MIRALLES, Ángela: Biotecnología, dignidad y derecho: bases para un diálogo. Barañáin (Navarra), EUNSA, 2004.

González Pérez, Jesús: La dignidad de la persona. Madrid, Civitas, 1986.

JunQuera De Estéfani, RAFAel: "El Bioderecho". En MARCOS DEL CANO, Ana María (coord.): Bioética y Derechos Humanos. Madrid, UNED, 2011.

JunQuera De Estéfani, Rafael: "Los Derechos Humanos en la era de la Biotecnología”. En MARTÍNEZ MORÁN, Narciso (ed.): Utopía y realidad de los Derechos Humanos en el cincuenta aniversario de su Declaración Universal. Madrid, UNED, 1999.

Lasanta, Pedro Jesús: Abortar, ¿es justo?, ¿es bueno? ... Logroño, Horizonte, 2009.

Marcos Del Cano, Ana María: "La autonomía del paciente en los supuestos de incapacidad". En JUNQUERA DE ESTÉFANI, Rafael 
(dir.): Bioética y bioderecho. Reflexiones jurídicas ante los retos bioéticos. Granada, Comares, 2008.

Marcos Del Cano, Ana María: "La Bioética y el Bioderecho desde los Derechos Humanos". En MARCOS DEL CANO, Ana María (coord.): Bioética y Derechos Humanos. Madrid, UNED, 2011.

Martínez Morán, Narciso: "Los derechos humanos como límite a la libertad en las investigaciones biomédicas». En JUNQUERA DE ESTÉFANI, Rafael (dir.): Bioética y bioderecho. Reflexiones jurídicas ante los retos bioéticos. Granada, Comares, 2008.

Postigo Solana, Elena y Díaz De Terán Velasco, Ma Cruz: "Nueva eugenesia: la selección de embriones in vitro". En BALLESTEROS LLOMPART, Jesús y APARISI MIRALLES, Ángela: Biotecnología, dignidad y derecho: bases para un diálogo. Barañáin (Navarra), EUNSA, 2004.

RODRÍGUEZ MERINO, José María: Ética y derechos humanos en la era biotecnológica. Madrid, Dykinson, 2008.

Romeo Casabona, Carlos María: El Derecho y la Bioética ante los límites de la vida humana. Madrid, Centro de Estudios Ramón Areces, 1994.

Tezanos Tortajada, José Félix: La sociedad dividida. Estructuras de clases y desigualdades en las sociedades tecnológicas. Madrid, Biblioteca Nueva, 2005. 
